\title{
Role of GLUT4 on angiotensin 2-induced systemic and renal hemodynamics
}

\author{
This article was published in the following Dove Press journal: \\ Journal of Experimental Pharmacology \\ 4 April 2013 \\ Number of times this article has been viewed
}

\author{
Ighodaro Igbe' \\ Eric Kelly Omogbai' \\ Adebayo O Oyekan² \\ 'Department of Pharmacology and \\ Toxicology, Faculty of Pharmacy, \\ University of Benin, Nigeria; ${ }^{2}$ Center \\ for Cardiovascular Diseases, College \\ of Pharmacy and Health Sciences, \\ Texas Southern University, Houston, \\ Texas, USA
}

\begin{abstract}
Cross-talk between insulin and the renin angiotensin system signaling system shows that angiotensin 2 (A2) negatively modulates insulin signaling by stimulating multiple serine phosphorylation events in the early stages of the insulin-signaling cascade; however, the biological actions of A2 on insulin sensitivity remain controversial. Preservation of glucose transporter 4 (GLUT4) expression during hypertension has been shown to prevent the increased vascular reactivity associated with hypertension. This study tested the hypothesis that GLUT4 contributes to the renal actions of A2. In the euvolemic anesthetized rat, acute infusion of the GLUT4 antagonist, indinavir ( $1 \mathrm{mg} / \mathrm{kg} /$ minute), enhanced an A2-induced increase in mean arterial blood pressure (MABP) $(P<0.01)$, but attenuated an A2-induced increase in medullary blood flow $(\mathrm{MBF})$ and glomerular filtration rate $(P<0.01)$. Insulin, a GLUT4 activator (20 $\mathrm{mU} / \mathrm{kg} /$ minute and $40 \mathrm{mU} / \mathrm{kg} /$ minute), decreased basal MABP and urine volume $(P<0.05)$, but it increased MBF, and these effects were reversed and blunted by indinavir. Subchronic indinavir treatment ( $80 \mathrm{mg} / \mathrm{kg} /$ day orally for 15 days) did not affect A2-induced changes in MABP, cortical blood flow, and MBF, but significantly decreased basal MBF $(P<0.01)$ and global kidney perfusion $(P<0.05)$. We concluded that acute but not subchronic inhibition of GLUT4 alters A2-induced changes in systemic and renal hemodynamics by attenuating A2-induced increase in MBF and glomerular filtration rate.
\end{abstract}

Keywords: angiotensin 2, indinavir, hemodynamics, GLUT4, medullary blood flow

\section{Introduction}

Glucose transporter 4 (GLUT4), the insulin-dependent, transmembrane glucose facilitative transport molecule, plays a decisive role in insulin-dependent cardiac glucose metabolism, myocardial and vascular stiffness, ${ }^{1,2}$ osmolarity, as well as compartmental water distribution and homeostasis. ${ }^{3}$ GLUT4 is present at high levels in fat, skeletal muscle, and cardiac muscle and is also expressed at lower levels in other tissues, including the kidneys. Recent studies have shown an intensive GLUT4 expression in the smooth muscle cells of the renal afferent vasculature, in the renal glomerulus of normal rat kidneys, ${ }^{4}$ in proximal tubules, in a convoluted segment of distal tubules connected with juxtaglomerular apparatus, and in the epithelial cells of the thick ascending loop of Henle. ${ }^{5,6}$ Cross-talk between insulin and the renin angiotensin signaling system has drawn great attention because hypertension and insulin resistance often coexist and are leading risk factors for cardiovascular diseases. ${ }^{7}$

Several lines of evidence have shown that angiotensin 2 (A2) plays an important role in the development of hypertension, cardiovascular disease, and insulin resistance..$^{8,9}$ Hence, agents that inhibit A2 actions, such as the A2 converting enzyme inhibitors
Correspondence: Ighodaro lgbe Department of Pharmacology and Toxicology, Faculty of Pharmacy, PMB II 54 University of Benin, Benin City, Nigeria

Tel +23 48I 66058559

Email igbe.ighodaro@uniben.edu 
and A2 receptors blockers not only reduce blood pressure, but also improve insulin sensitivity in hypertensive and insulin-resistant patients. ${ }^{10,11}$ Evidence has been provided that A2 interferes with insulin signaling in vascular cells mainly by insulin-induced tyrosine phosphorylation of insulin receptor substrate 1 (IRS-1), ${ }^{9}$ thus impairing the vasodilator effects of insulin mediated by the IRS-1/PI3-kinase/Akt/endothelial NO synthase pathway. ${ }^{12}$ Alternatively, A2 may decrease the IRS-1/PI3-kinase association via the activation or upregulation of a protein-tyrosine phosphatase, ${ }^{12}$ and this thereby negatively modulates insulin signaling of the early components of the insulin-signaling cascade. Several studies have shown that rat and murine models of hypertension are associated with a marked decrease in GLUT4 expression in arterial smooth muscle. ${ }^{13,14}$ This reduction in GLUT4 levels corresponds to enhanced arterial sensitivity to agonists such as 5-hydroxytryptamine (5-HT) and norepinephrine (NE). In addition, preservation of GLUT4 expression during hypertension has been shown to prevent the increased vascular reactivity associated with hypertension. ${ }^{15}$ On the other hand, the inhibition of GLUT4 with indinavir has been shown to decrease glomerular filtration rate (GFR), renal blood flow (RBF), and nitrous oxide (NO) excretion without having any significant effect on blood pressure, ${ }^{16}$ indicating a mutually exclusive effect by GLUT4 on systemic versus regional hemodynamics. Based on these observations, we evaluated the inhibition of GLUT4 on A2-induced changes in systemic and renal hemodynamics in an attempt to test the hypothesis that GLUT4 plays a role in the renal actions of A2.

\section{Materials and methods Drugs and chemicals}

Insulin from bovine pancreas, bovine serum albumin, inulin, sulfanilamide, N-(1-naphthyl)ethylenediamine, phosphoric acid, trichloroacetic acid, sodium nitrite, A2, sulfuric acid (Sigma-Aldrich, St Louis, MO, USA), dextrose (EM Science, Gibbstown, NJ, USA), citric acid and sodium citrate (Thermo Fisher Scientific, Waltham, MA, USA), indinavir (Crixivan; Merck and Co, Inc, Whitehouse Station, NJ, USA).

\section{Animals}

Experiments were conducted on male Sprague Dawley rats (300-350 g body weight) (Harlan Sprague Dawley, Houston, TX, USA) in accordance with the Care and Use of Laboratory Animals guidelines of the National Institutes of Health. Protocols for the study were approved by the Institutional Animal Care and Use Committee. Animals were maintained on standard rat food (Purina Chow; Purina, St Louis,
MO, USA), and they were allowed ad libitum access to water and food prior to the experiments.

\section{Acute studies \\ Surgical preparation}

Animals were anesthetized with thiobutabarbital (Inactin ${ }^{\circledR}$; Sigma-Aldrich), $100 \mathrm{mg} / \mathrm{kg}$ intraperitoneally and placed on a heated platform to maintain body temperature at $37^{\circ} \mathrm{C}$. Both tail veins were cannulated with a 25 -gauge butterfly needle (Vacutainer; Becton and Dickson, Franklin Lakes, NJ, USA) for the infusion or administration of drugs. The urethra was tied, and the urinary bladder was exposed by an abdominal incision. A cannula, polyethylene tubing, (PE-205) was inserted to drain and collect urine at 30-minute intervals. Dead space was minimized by a ligature that functionally excluded a large part of the bladder. A tracheotomy using PE-250 was performed for spontaneous ventilation, and a cannula (PE-50) was placed in the left carotid artery to monitor blood pressure. Mean arterial blood pressure (MABP) was measured with a pressure transducer (model BLPR2; World Precision Instruments, Inc, Sarasota, FL, USA) to a signal manifold (Transbridge, model TBM-4; World Precision Instruments, Inc) and recorded on a data acquisition system (model DI720; DATAQ Instruments, Inc, Akron, OH, USA). The left kidney was exposed by an abdominal incision, and intra-RBF was measured simultaneously by laser-Doppler flowmeter (system 5000, version 1.20; PeriFlux, Perimed AB, Stockholm, Sweden) via a surface probe (model PF 407) to measure cortical blood flow (CBF) or using an optical fiber laser-Doppler probe (model PF 402) fixed to a micromanipulator and placed in the medulla ( $5 \mathrm{~mm}$ below the kidney surface) to measure medullary blood flow (MBF). $\mathrm{CBF}$ and $\mathrm{MBF}$ were recorded as perfusion units (PU). An intravenous bolus dose of inulin $(20 \mathrm{mg} / \mathrm{kg})$ in normal saline was administered through the tail vein followed by a maintenance infusion (20 $\mathrm{mg} /$ hour) in normal saline throughout the experiment to maintain euvolemia. Clearance of inulin was determined to evaluate GFR using the anthrone method. ${ }^{17}$ Rats were allowed to equilibrate for approximately 45 minutes, or until urine flow from the bladder was steady. After this postsurgical equilibration period, a 30-minute control clearance period was obtained, and urine was collected at the end of the clearance period. Arterial blood $(0.2 \mathrm{~mL})$ was collected from the carotid artery into $3.2 \%$ sodium citrate during the middle of a 30-minute urine collection period and immediately centrifuged at $6000 \times \mathrm{g}$ for 1 minute using a microcentrifuge (Model RS-102; APR\&D Inc, Center, Minnesota, USA) to obtain plasma. An equal amount of normal saline was infused for volume replacement. 
Studies of indinavir effect on angiotensin 2-mediated systemic and renal hemodynamics

Rats were infused through the tail vein with the GLUT4 antagonist, indinavir ( $1 \mathrm{mg} / \mathrm{kg} / \mathrm{minute})$, or vehicle (1 mL/hour) (dilute $\mathrm{H}_{2} \mathrm{SO}_{4}, \mathrm{pH} 4$ ) at a constant rate throughout the experiment. Ten minutes after the commencement of infusion, graded doses of A2 $(300 \mathrm{ng} / \mathrm{kg} /$ minute and $1000 \mathrm{ng} / \mathrm{kg} /$ minute) each lasting for 30 minutes were infused concurrently. A tracheotomy (PE-250) was performed for spontaneous ventilation, and a cannula (PE-50) was placed in the left carotid artery to monitor blood pressure. MABP, $\mathrm{CBF}$, and $\mathrm{MBF}$ were measured as described above, and $\mathrm{CBF}$ and MBF were recorded as PU. Urine was collected every 30 minutes, while blood was collected at the midpoint of every 30-minute urine collection, and GFR was determined by inulin clearance using the anthrone method. Urine volume (UV) was determined gravimetrically.

\section{Studies of indinavir effect on insulin (GLUT4} agonist)-mediated systemic and renal hemodynamics Rats were infused with graded doses of insulin $(20 \mathrm{mU} / \mathrm{kg}$ / minute and $40 \mathrm{mU} / \mathrm{kg} /$ minute $)$, or vehicle $(0.5 \%$ bovine serum albumin in normal saline, $1 \mathrm{~mL} /$ hour), each dose lasting 30 minutes. Ten minutes after the beginning of insulin infusion, a $50 \%$ dextrose solution (in saline) was infused at a variable rate to maintain baseline blood glucose level $(98 \pm 0.1 \mathrm{mg} / \mathrm{dL})$ as monitored by frequent arterial blood glucose determinations (Glucometer Prestige; Walgreen Co, Deerfield, IL, USA) performed at 10-minute intervals using blood from the tail. In another group of rats, indinavir $(1 \mathrm{mg} / \mathrm{kg} /$ minute) was infused 10 minutes prior to a concurrent infusion of graded doses of insulin $(20 \mathrm{mU} / \mathrm{kg} /$ minute and $40 \mathrm{mU} / \mathrm{kg} /$ minute). Both drugs were infused at a constant rate throughout the experiment. MABP, CBF, and MBF were measured simultaneously. Urine and blood were collected as stated above for GFR estimation. UV was determined gravimetrically.

\section{Subchronic studies}

Male Sprague Dawley rats were treated with indinavir $(80 \mathrm{mg} / \mathrm{kg} /$ day $)$ or vehicle ( $0.05 \mathrm{M}$ citric acid solution) by oral gavage for 15 days. ${ }^{16}$ This dose regimen was shown to significantly reduce urinary NO, GFR, and RBF in rats. At the end of treatment, animals were placed in metabolic cages for 24-hour urine collection. Animals were then anesthetized with thiobutabarbital (Inactin), $100 \mathrm{mg} / \mathrm{kg}$ intraperitoneally. An incision, approximately $5 \mathrm{~cm}$ long, was made on the left side of the abdomen and was kept open using a clamp to expose the left kidney. A laser scanner (Moor Instruments
Inc, Axminster, UK) was positioned directly over the left kidney for the measurement of whole kidney perfusion. Two repetitive scans were performed and the mean value for each kidney was determined. Renal perfusion was expressed as PU per unit area of kidney.

Immediately after determination of whole kidney perfusion, the tail veins were cannulated for infusion or drug administration, and tracheostomy was performed for spontaneous ventilation. The urethra was tied and the urinary bladder catheterized for urine collection. A cannula was placed in the left carotid artery to measure MABP, and a left laparatomy was performed to monitor the $\mathrm{CBF}$ and $\mathrm{MBF}$.

Graded doses of A2 (300 $\mathrm{ng} / \mathrm{kg} /$ minute and $1000 \mathrm{ng} / \mathrm{kg} /$ minute), each lasting for 30 minutes, were infused concurrently. MABP, $\mathrm{CBF}$, and MBF were measured simultaneously. Urine was collected every 30 minutes, while blood was collected at the midpoint of every 30 -minute urine collection to determine GFR by inulin clearance. UV was also determined.

\section{Urine and plasma inulin measurements}

Urine and plasma inulin concentrations were measured using the standard colorimetric techniques, ${ }^{17}$ and GFR was calculated as the ratio of urine and plasma inulin concentrations multiplied by urine flow.

\section{Statistical analysis}

All data were expressed as mean \pm standard error of the mean. Changes in systemic and renal hemodynamics were expressed as absolute values and absolute changes from baseline. The effects of A2 and indinavir were analyzed using a two-way analysis of variance followed by Tukey's multiple comparison test when appropriate.

\section{Results}

\section{Effect of acute inhibition of GLUT4 on systemic and renal hemodynamics induced by angiotensin 2 infusion}

In Figure 1, acute indinavir infusion ( $1 \mathrm{mg} / \mathrm{kg} /$ minute) significantly enhanced A2-induced increase in MABP $(P<0.05)$, but only at the $1000 \mathrm{ng} / \mathrm{kg} /$ minute dose, and it had the tendency to attenuate the A2-induced increase in MBF, but it did not affect CBF. As illustrated in Figure 2, A2 produced an unexpected increase in UV, while simultaneous indinavir administration did not produce any significant change in UV. The increase in UV elicited by A2 may be due to pressure natriuresis. In Figure 3, A2 produced an increase in GFR at a dose of $1000 \mathrm{ng} / \mathrm{kg} /$ minute, and this effect was attenuated by 

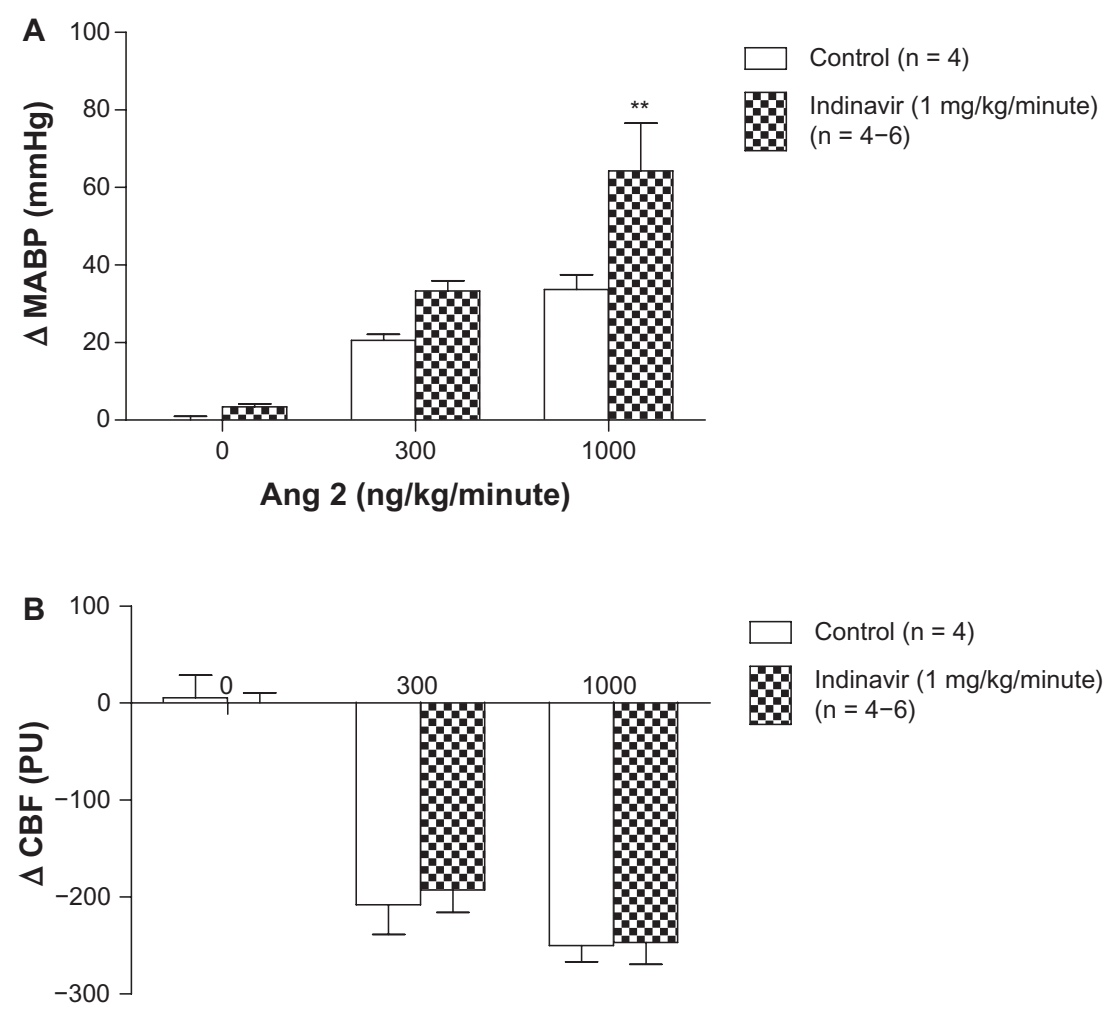

Ang 2 (ng/kg/minute)

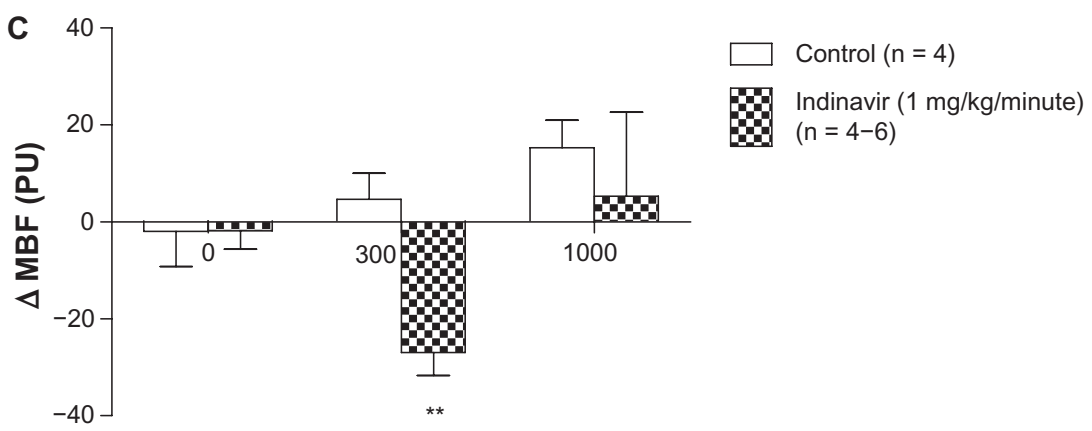

Ang 2 (ng/kg/minute)

Figure I Effect of GLUT4 inhibition by indinavir on the effects produced by acute Ang 2 infusion on systemic and renal hemodynamics. Effect of GLUT4 inhibition by indinavir on the effects produced by acute Ang 2 infusion on systemic $(\mathbf{A})$ and renal (B and $\mathbf{C}$ ) hemodynamics.

Note: $* * P<0.01$ versus control.

Abbreviations: GLUT4, glucose transporter 4; Ang 2, angiotensin 2; n, number; MABP, mean arterial blood pressure; CBF, cortical blood flow; MBF, medullary blood flow.

acute indinavir administration $(P<0.05)$. These data imply that GLUT4 may attenuate A2-induced increase in GFR.

\section{Effect of subchronic indinavir administration} on basal systemic and renal hemodynamics

The role of GLUT4 on basal systemic and renal hemodynamics after subchronic administration of indinavir was evaluated. Figure 4 illustrates that the subchronic inhibition of GLUT4 did not change basal MABP or $\mathrm{CBF}$, but significantly reduced $\mathrm{MBF}$ (113 \pm 8 PU) compared to control (176 \pm 19 PU, $P<0.01)$.
These data suggest that GLUT4 is involved in the maintenance of basal renal medullary perfusion.

Effect of angiotensin 2 infusion on systemic and renal hemodynamics after subchronic indinavir administration

The effect of the subchronic inhibition of GLUT4 on A2-mediated effects on systemic and renal hemodynamics was evaluated in animals treated with indinavir ( $80 \mathrm{mg} / \mathrm{kg} /$ day orally for 15 days). Figure 5 illustrates that 




Figure 2 Effect of GLUT4 inhibition by indinavir on the effects of acute Ang 2 infusion on urine output. Abbreviations: GLUT4, glucose transporter 4; ANG 2, angiotensin 2; n, number.

the subchronic administration of indinavir did not affect the changes in MABP, $\mathrm{CBF}$, and MBF induced by acute A2 administration, nor did it cause changes in urine output and GFR (Figures 6 and 7), but there was a reduction in global kidney perfusion $(P<0.05)$ (Figure 8 ). These data imply that GLUT4 did not contribute significantly to A2-mediated effects that were determined in these experiments, but they may be increasing overall intra-RBF.

\section{Effects of acute activation of GLUT4 on systemic} and renal hemodynamics in the absence or presence of acute indinavir administration

In order to evaluate the effects of acute activation of GLUT4 on basal systemic and renal hemodynamics in the absence or presence of a GLUT4 antagonist, animals were treated with insulin, a GLUT4 activator, at doses of $20 \mathrm{mU} / \mathrm{kg} / \mathrm{minute}$ and $40 \mathrm{mU} / \mathrm{kg} / \mathrm{minute}$ in the absence or presence of acute indinavir administration. Figure 9 shows that insulin decreased basal MABP and increased MBF in a dose-related fashion with minimal effects on CBF. The insulin-induced decrease in MABP and subsequent increase in MBF were reversed and blunted, respectively, by acute infusion of indinavir. Figure 10 illustrates that, as expected, insulin infusion reduced UV in a dose-related manner, and this effect was attenuated by indinavir $(P<0.05)$. However, Figure 11 illustrates that insulin produced no significant change in GFR. These data suggest that GLUT4 activation increases MBF, but it does not translate into an increase in



Ang 2 (ng/kg/minute)

Figure 3 Effect of GLUT4 inhibition by indinavir on the effects of acute Ang 2 infusion on GFR.

Note: $* P<0.05$ versus control.

Abbreviations: GLUT4, glucose transporter 4; GFR, glomerular filtration rate; Ang 2, angiotensin 2; n, number. 
A



B

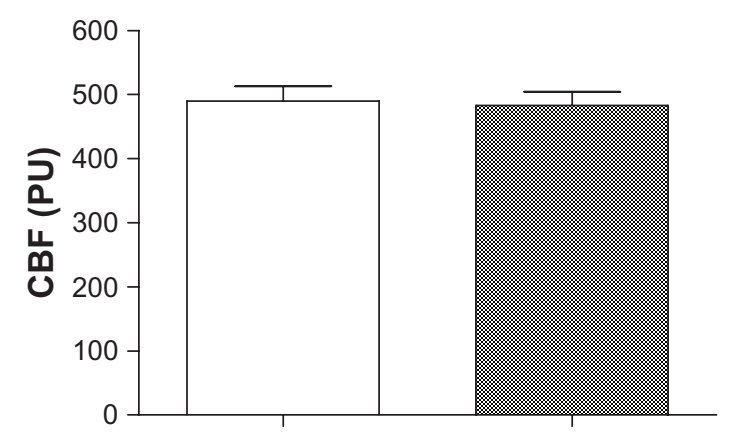

$$
\begin{aligned}
& \square \text { Control }(n=7) \\
& \square \text { Indinavir }(n=7)
\end{aligned}
$$

C

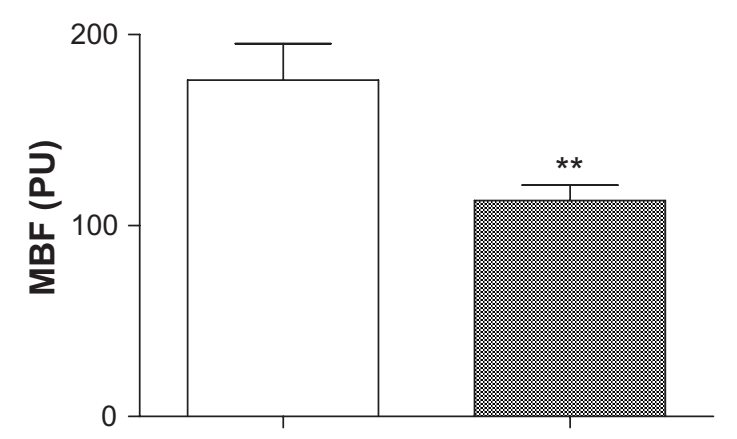

Figure 4 Basal values for systemic and renal hemodynamics in the presence of subchronic inhibition of GLUT4 with indinavir (80 mg/kg/day for 15 days). Basal values for systemic (A) and renal (B and C) hemodynamics in the presence of subchronic inhibition of GLUT4 with indinavir ( $80 \mathrm{mg} / \mathrm{kg} / \mathrm{day}$ for 15 days).

Notes: Vehicle for indinavir was $0.05 \mathrm{M}$ citric acid $(0.3 \mathrm{~mL} /$ day $)$; ${ }^{* *} P<0.0$ I versus control.

Abbreviations: GLUT4, glucose transporter 4; n, number; MABF, mean arterial blood flow; CBF, cortical blood flow; MBF, medullary blood flow.

urine output, thus implying that the stimulation of GLUT4 in the kidney may be acting through independent vascular and tubular mechanisms.

\section{Discussion}

Several studies have shown that A2 inhibits insulinstimulated glucose transport and GLUT4 translocation in multiple organs and tissues, ${ }^{18,19}$ including the intact rat heart and the rat aortic smooth muscle cells. ${ }^{20}$ Conversely, treatment with an angiotensin receptor type $1\left(\mathrm{AT}_{1}\right)$ blocker improved tyrosine phosphorylation of IRS-1, insulin receptor IRS-1/PI3-K association, and GLUT4 translocation to the plasma membrane. ${ }^{21}$ In the present study, acute inhibition of GLUT4 with indinavir enhanced an A2-induced increase in MABP, but attenuated A2-induced increase in MBF and GFR. These observations are consistent with studies that report that the abrogation of GLUT4 expression by genetic knockout is associated with both increased total force generation and enhanced sensitivity to agonists such as 5-HT and NE. ${ }^{14}$ In addition, the preservation of GLUT4 expression during hypertension would prevent the associated increase in vascular reactivity. ${ }^{15}$ 
A

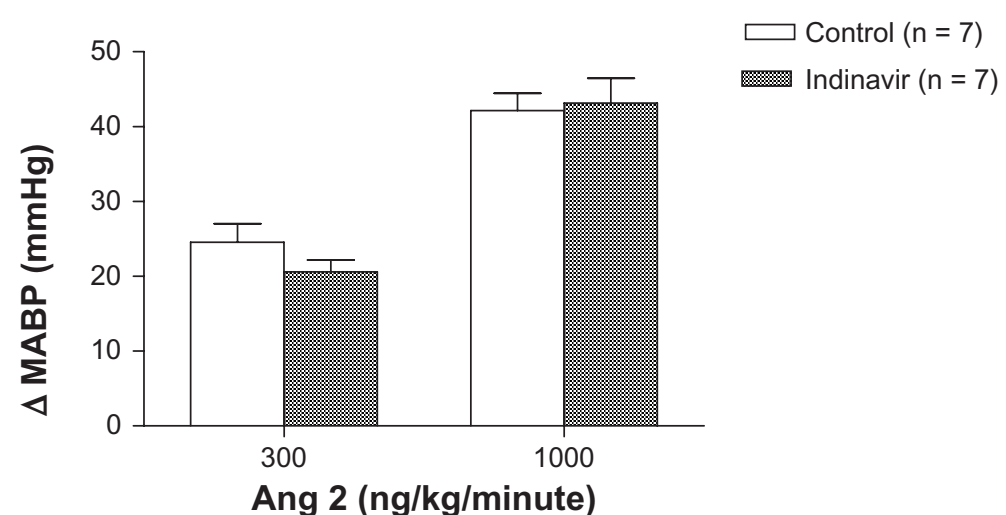

B



C

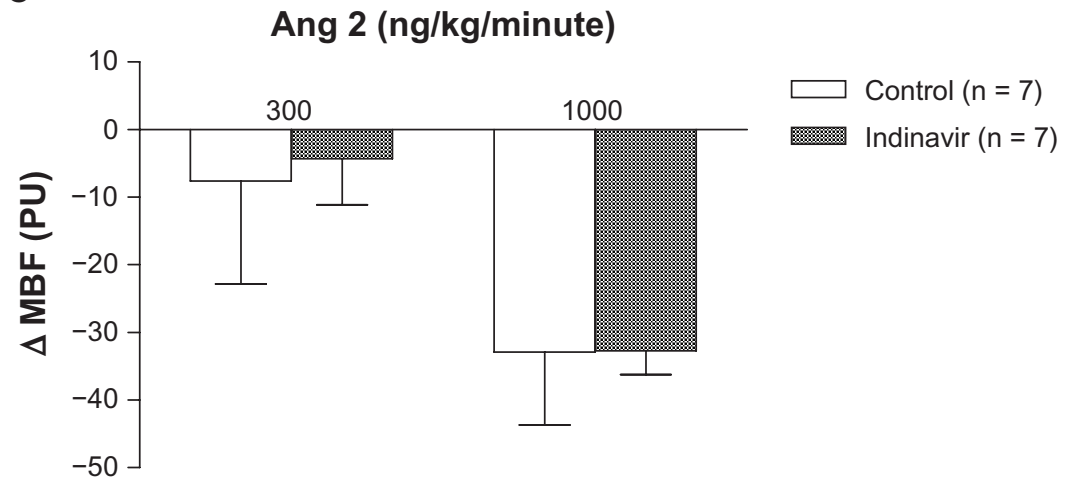

Figure 5 Effect of acute Ang 2 infusion on systemic and renal hemodynamics in the presence of subchronic inhibition of GLUT4 with indinavir (80 mg/kg/day for I5 days). Effect of acute Ang 2 infusion on systemic (A) and renal (B and C) hemodynamics in the presence of subchronic inhibition of GLUT4 with indinavir (80 mg/kg/day for 15 days).

Note: Vehicle for indinavir was $0.05 \mathrm{M}$ citric acid $(0.3 \mathrm{~mL} /$ day $)$

Abbreviations: Ang 2, angiotensin 2; GLUT4, glucose transporter 4; MABF, mean arterial blood flow; n, number; CBF, cortical blood flow; MBF, medullary blood flow.

A2 has been shown to increase renal MBF via stimulation of AT type $2\left(\mathrm{AT}_{2}\right)$ receptors, and $\mathrm{AT}_{2}$ is associated with increased NO production, ${ }^{22,23}$ leading to vasodilation and an increase in medullary flow. Insulin-stimulated translocation of GLUT4 is associated with an increase in NO production by a pathway involving IRS-1/PI3-kinase/Akt/endothelial NO synthase. ${ }^{24}$ Therefore, inhibition of GLUT4 and the ensuing decrease in NO production/medullary blood flow probably accounts for the decreased A2-induced increase in MBF.

A2 conserves salt and water through a combination of the hemodynamic and tubular epithelial cell sodium chloride and water transport mechanisms. ${ }^{25}$ Thus, A2 elicited a direct effect on the proximal tubule apical sodium/hydrogen exchanger 


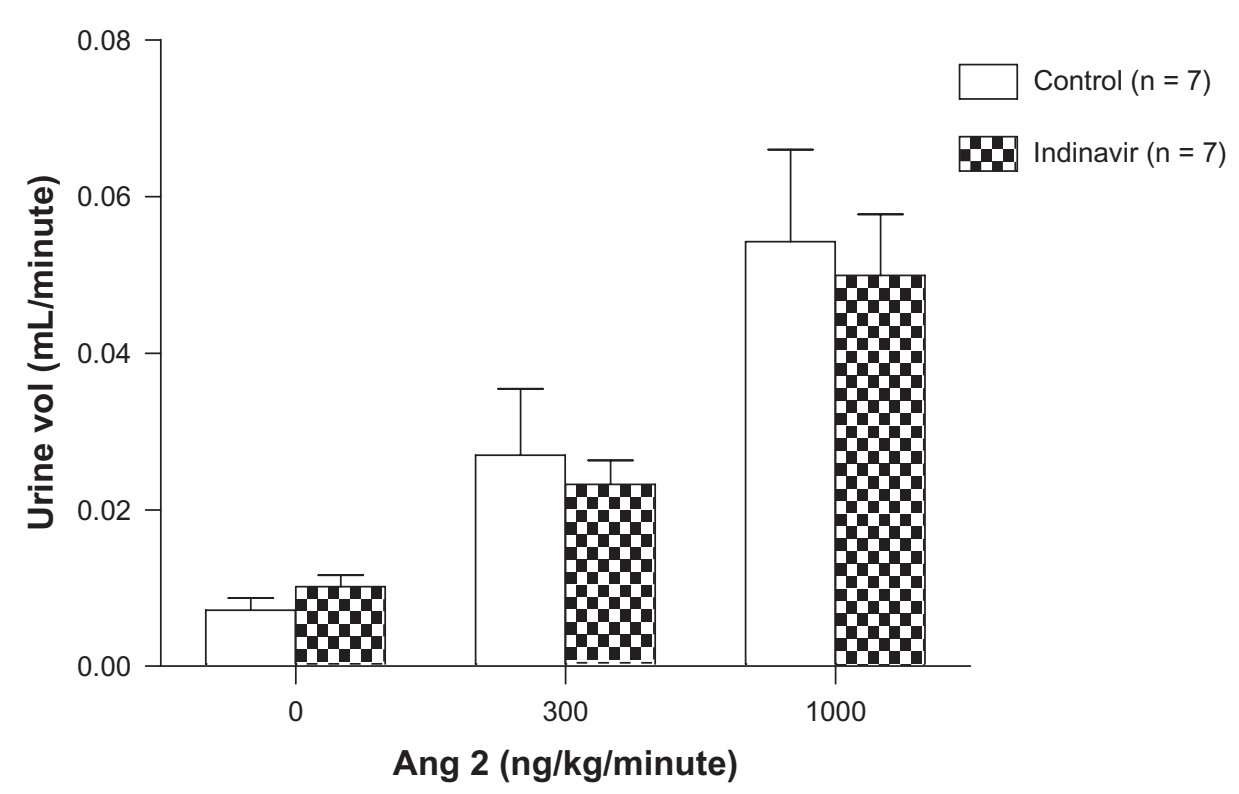

Figure 6 Effect of acute Ang 2 infusion on urine output in the presence of subchronic inhibition of GLUT4 with indinavir (80 mg/kg/day for 15 days). Note: Vehicle for indinavir was $0.05 \mathrm{M}$ citric acid $(0.3 \mathrm{~mL} /$ day $)$.

Abbreviations: Ang 2, angiotensin 2; GLUT4, glucose transporter 4; n, number.

and on the basolateral sodium-bicarbonate cotransporter, ${ }^{25}$ stimulating proximal tubular $\mathrm{Na}^{+}$and water reabsorption at low doses, but inhibiting it at higher doses. A2 can also stimulate transport activity in distal nephron segments, ${ }^{26,27}$ and thereby directly stimulates sodium reabsorption in distal nephron segments via the proximal tubule apical sodium/ hydrogen exchanger, $\mathrm{Na}^{+} \mathrm{Cl}^{-}$cotransporter, epithelial sodium channel, potassium channel, and $\mathrm{H}^{+}-\mathrm{ATPase}$ transport mechanisms. ${ }^{26} \mathrm{~A} 2$ produced an unexpected increase in UV, while simultaneous indinavir infusion did not produce any significant change in UV. The increase in UV elicited by high dose of A2 may be due to pressure natriuresis. A2 also exerts several effects that may alter the GFR by constricting the afferent arteriole and the mensangial cells to decrease GFR, or by constricting the efferent arterioles to increase GFR, the net effect depending on the physiological state. In this study, A2 produced an expected decrease in urine output at low doses, probably through an $\mathrm{AT}_{1}$ receptor-mediated decrease in RBF and/or stimulation of sodium transport in the proximal tubule and distal segments of nephron; ${ }^{28}$ however, it paradoxically increased urine flow at high dose due to pressure natriuresis. ${ }^{29}$ The attenuation of A2-induced

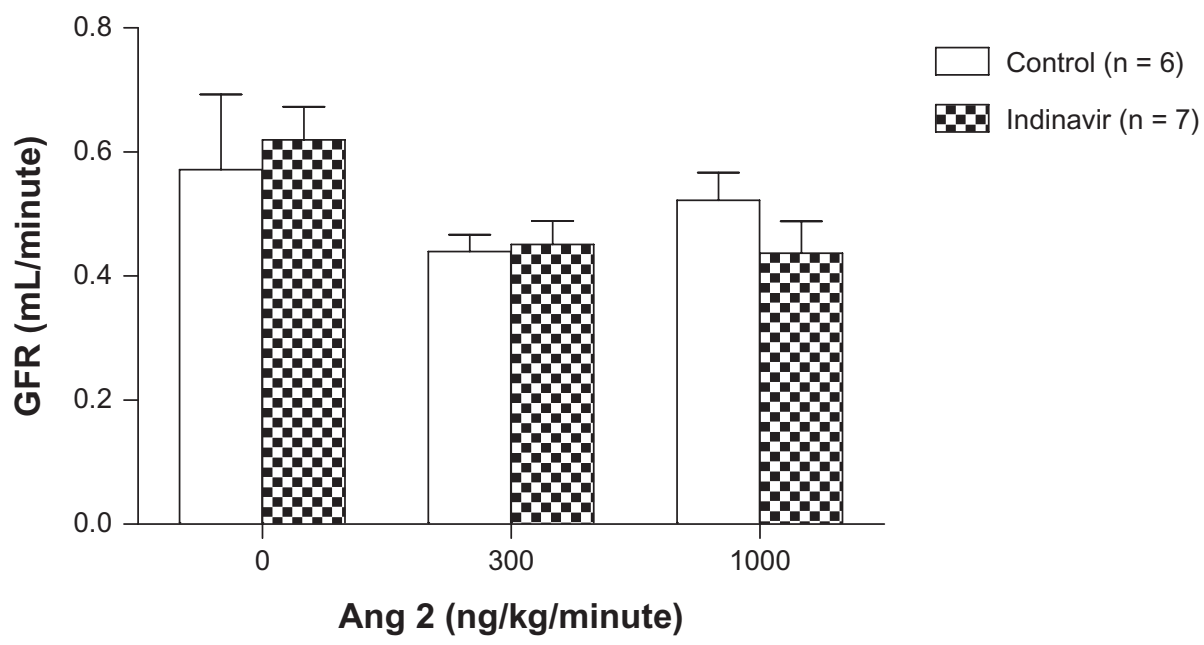

Figure 7 Effect of acute Ang 2 infusion on GFR in the presence of subchronic inhibition of GLUT4 with indinavir ( $80 \mathrm{mg} / \mathrm{kg} / \mathrm{day}$ for I5 days). Note: Vehicle for indinavir was $0.05 \mathrm{M}$ citric acid $(0.3 \mathrm{~mL} /$ day).

Abbreviations: Ang 2, angiotensin 2; GFR, glomerular filtration rate; GLUT4, glucose transporter 4; n, number. 
A


B

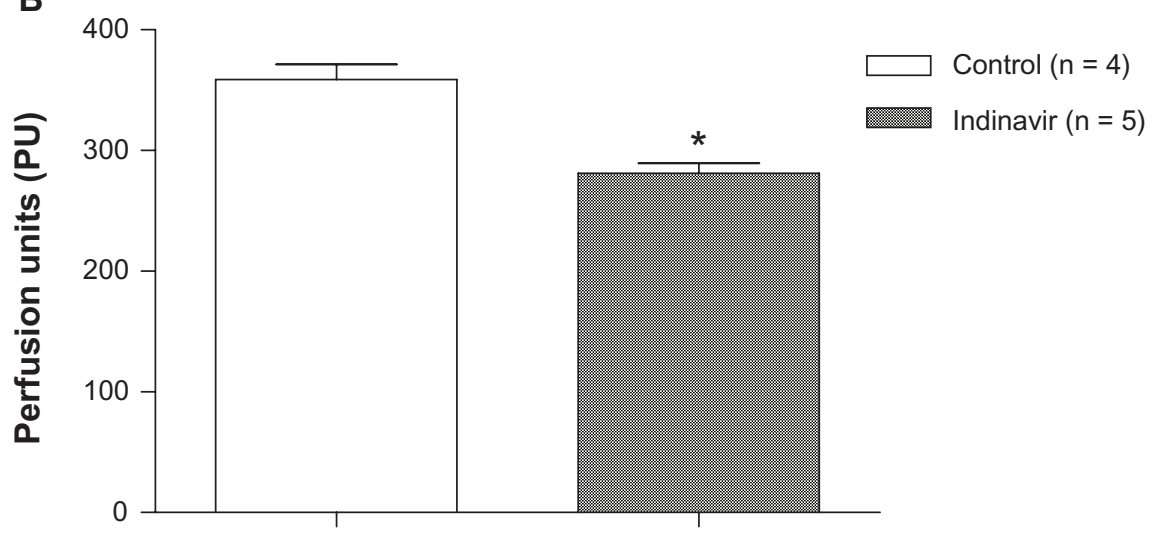

Figure 8 Effect of subchronic inhibition of GLUT4 with indinavir $(80 \mathrm{mg} / \mathrm{kg} /$ day for 15 days $)$ on whole kidney perfusion. A representative scan of whole kidney blood perfusion using a laser scanner in control $(\mathbf{A})$ and indinavir-treated rats; and the representation of the quantification of whole kidney perfusion (B).

Notes: $P<0.05$ versus vehicle. Vehicle for indinavir was $0.05 \mathrm{M}$ citric acid $(0.3 \mathrm{~mL} /$ day $)$.

Abbreviations: GLUT4, glucose transporter 4; n, number.

reduction in urine output following GLUT4 inhibition may occur through a mechanism that probably involves a direct interaction between the inhibition of GLUT4 and A2 receptors at sites of A2-induced sodium reabsorption in the nephron. A decrease in glucose transport following GLUT4 inhibition is expected to increase GFR as a result of decrease in intracellular adenosine triphosphate (ATP), and subsequent activation of $\mathrm{K}_{\text {ATP }}$ channels leading to vasodilation. ${ }^{4,20}$ In the present study, GLUT4 inhibitioninduced attenuation of the unexpected increase in GFR induced by the high dose of A2 could be explained by the known A2 inhibition of $\mathrm{K}_{\text {ATP }}$ channels. ${ }^{30,31}$ A previous study reports that chronic indinavir treatment induces moderate hyperbilirubinemia and attenuates A2-dependent hypertension in mice, ${ }^{32}$ and this may be through improved renal hemodynamics and GFR..$^{33}$ The increase in bilirubin levels in A2-treated mice may result in a greater decrease in vascular superoxide $\left(\mathrm{O}_{2}\right)$ levels and an increase in $\mathrm{NO}$ bioavailability. Plausible as this is, it varies from data obtained in the present study, probably because the low dose of indinavir used $(80 \mathrm{mg} / \mathrm{kg} /$ day $)$ in the present study is lower than the high dose of $500 \mathrm{mg} / \mathrm{kg} /$ day that produced hyperbilirubinemia in previous studies. ${ }^{16,32}$

After subchronic inhibition of GLUT4, there were no changes in basal MABP or CBF, but there was a significant reduction in MBF. The reduction in basal MBF was similar to the results with acute GLUT4 inhibition. The lack of change in both systemic and renal hemodynamics after subchronic inhibition suggests that GLUT4 may not interact with A2 when activated chronically. Alternatively, there could be compensatory changes in glucose uptake or cellular signaling in response to the chronic inhibition of GLUT4-mediated glucose uptake as compared to the effects of acute inhibition of GLUT4-mediated uptake. At present, there are no data that support either of these possibilities, but NE and 5-HT-induced contractility was attenuated after acute inhibition of GLUT4, while contractility to NE and 5-HT was potentiated in the GLUT4 knockout mice, ${ }^{14}$ suggesting that the chronic absence or reduction of GLUT4 expression in vascular smooth muscle cells (VSMCs) leads to opposite effects. 


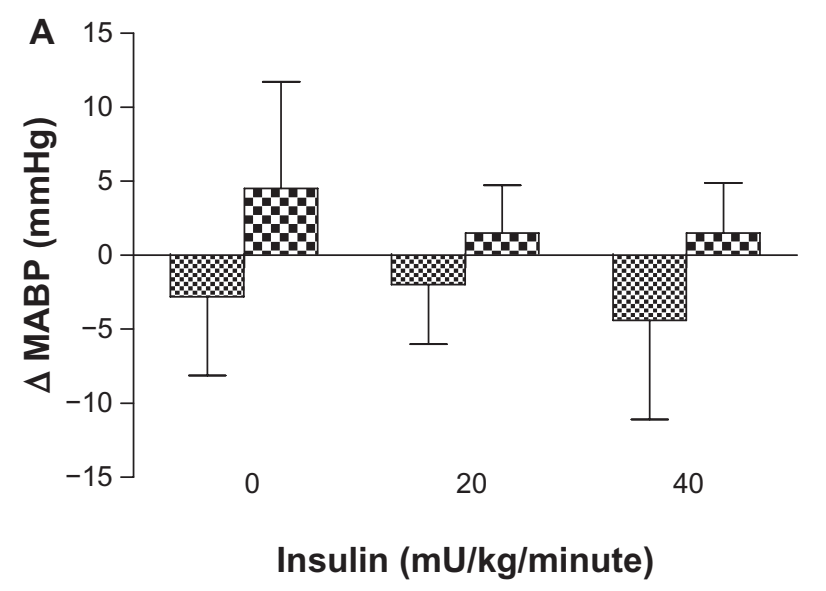

$\begin{array}{ll}89 & \text { Insulin }(n=5) \\ & \text { Insulin + indinavir }(n=4)\end{array}$

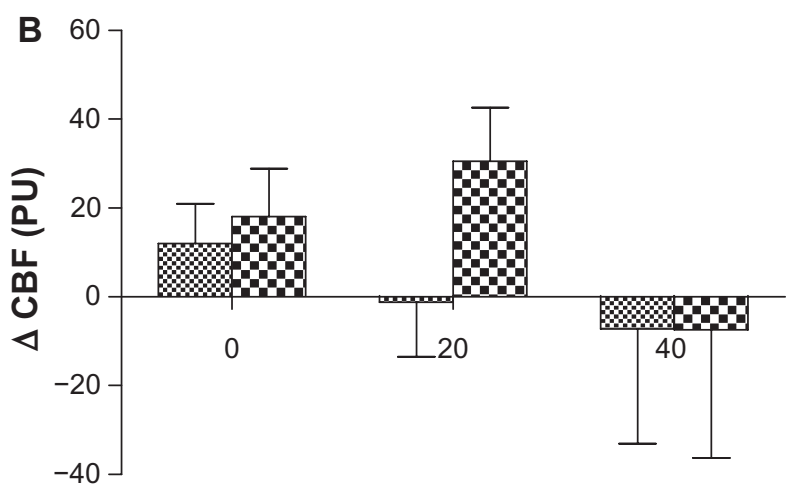

Insulin $(n=5)$
Insulin + indinavir $(n=4)$

Insulin (mU/kg/minute)



\% Insulin $(n=5)$

EDsulin + indinavir $(n=4)$

Figure 9 Effect of acute activation of GLUT4 with insulin ( $20 \mathrm{mU} / \mathrm{kg} /$ minute and $40 \mathrm{mU} / \mathrm{kg} / \mathrm{minute})$ on systemic and renal hemodynamics in the presence or absence of acute indinavir administration. Effect of acute activation of GLUT4 with insulin $(20 \mathrm{mU} / \mathrm{kg} /$ minute and $40 \mathrm{mU} / \mathrm{kg} /$ minute) on systemic (A) and renal (B and C) hemodynamics in the presence or absence of acute indinavir administration.

Note: $* P<0.05$ versus control.

Abbreviations: GLUT4, glucose transporter 4; MABF, mean arterial blood flow; n, number; CBF, cortical blood flow; MBF, medullary blood flow.

Recent studies have shown that insulin acts as a pressor as well as a depressor, depending on experimental circumstance and physiological state. ${ }^{34,35}$ In evaluating the effects of insulin in the absence or presence of indinavir on systemic and renal hemodynamics, insulin decreased basal MABP, and this effect was reversed by indinavir, thus confirming that GLUT4 was involved in arterial blood pressure regulation. ${ }^{13-15}$ The blunting of an insulin-induced increase in MBF by indinavir again confirms that the activation of GLUT4 will increase renal MBF, possibly through an increase in NO production. The doserelated reduction in UV by insulin obtained in the present study is in agreement with a previous report ${ }^{36}$ where the stimulation 


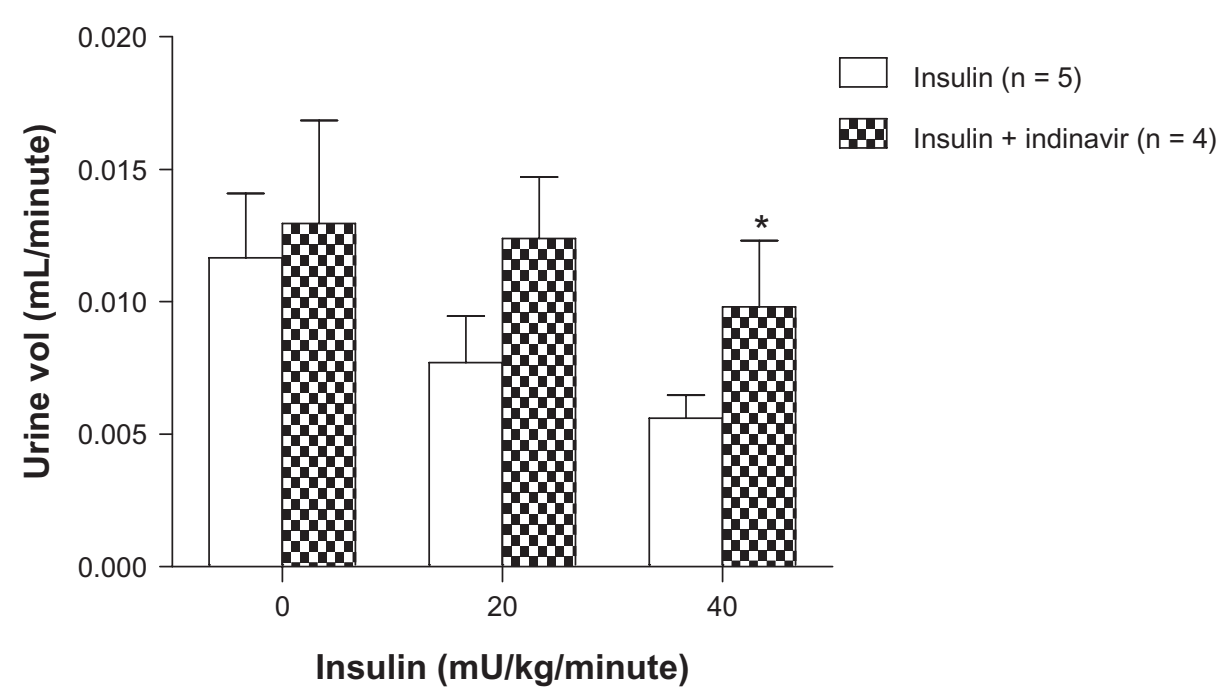

Figure 10 Effect of acute activation of GLUT4 with insulin $(20 \mathrm{mU} / \mathrm{kg} / \mathrm{minute}$ and $40 \mathrm{mU} / \mathrm{kg} / \mathrm{minute})$ on urine output in the presence or absence of acute indinavir administration.

Note: $* P<0.05$ versus control.

Abbreviations: GLUT4, glucose transporter 4; n, number.

of GLUT4 by insulin has been shown to enhance sodium and water retention in the renal tubules. This effect was blunted by GLUT4 inhibition, suggesting that GLUT4 activation may be exerting an indirect tubular effect. Though insulin is capable of stimulating mechanisms that promote both antinatriuresis and natriuresis, ${ }^{37-39}$ under the conditions of these experiments, the net effect appears to be that of increased sodium reabsorption and decreased urine output. Insulin infusion did not produce any significant changes in GFR; however, indinavir appears to increase GFR when infused concurrently with insulin in the present study, and this result may be explained by decreased glucose transport. GLUT4 inhibition leads to diminished ATP generation, subsequently resulting in increased activity of $\mathrm{K}_{\text {ATP }}$ and relaxation of the VSMC. This leads to increased GFR, as observed in the present study, when indinavir is infused concurrently with insulin. This is in agreement with a previous study, ${ }^{4}$ which showed that the decreased expression of GLUT4 in VSMCs of afferent renal microvasculature could lead directly to vasodilation and increased glomerular filtration. In conclusion, this study demonstrates that GLUT4 plays a role in A2-induced changes in systemic and renal hemodynamics.

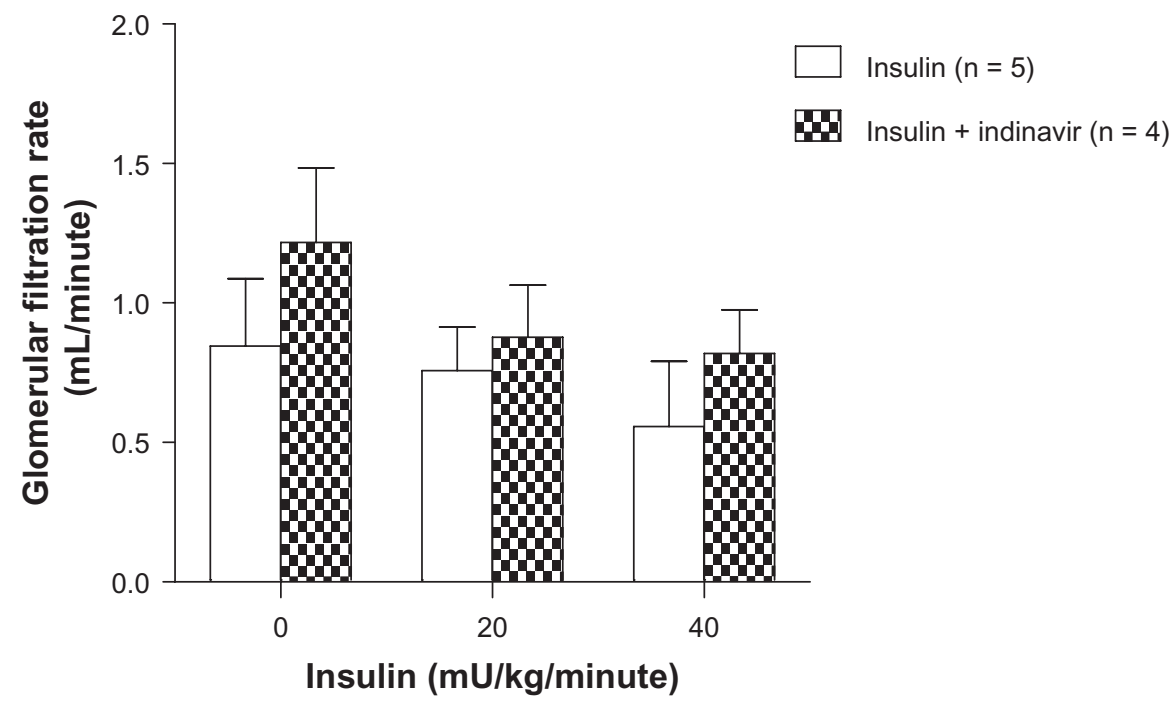

Figure II Effect of acute activation of GLUT4 receptor with insulin ( $20 \mathrm{mU} / \mathrm{kg} /$ minute and $40 \mathrm{mU} / \mathrm{kg} / \mathrm{minute})$ on glomerular filtration rate in the presence or absence of acute indinavir administration.

Abbreviations: GLUT4, glucose transporter 4; n, number. 


\section{Acknowledgments}

This study was supported by National Institutes of Health grant HL03674. The facilities of the RCMI program at Texas Southern University were used for this study.

\section{Disclosure}

The authors report no conflicts of interest in this work.

\section{References}

1. Kaczmarczyk SJ, Andrikopoulos S, Favaloro J, et al. Threshold effects of glucose transporter-4 (GLUT4) deficiency on cardiac glucose uptake and development of hypertrophy. J Mol Endocrinol. 2003;31(3):449-459.

2. Gasser R, Gasser S, Scherr E, Friehs I. Insulin-dependent transmembrane glucose transport in cardiovascular disease. Journal of Clinical and Basic Cardiology. 2006;9(1-4):1-3.

3. Pessin JE, Bell GI. Mammalian facilitative glucose transporter family: structure and molecular regulation. Ann Rev Physiol. 1992;54: 911-930.

4. Marcus RG, England R, Nguyen K, Charron MJ, Briggs JP, Brosius FC 3rd. Altered renal expression of the insulin-responsive glucose transporter GLUT4 in experimental diabetes mellitus. Am $J$ Physiol. 1994;267(5 Pt 2):F816-F824.

5. Anderson TJ, Martin S, Berka JL, James DE, Slot JW, Stow JL. Distinct localization of renin and GLUT-4 in juxtaglomerular cells of mouse kidney. Am J Physiol. 1998;274(1 Pt 2):F26-F33.

6. Hussar P, Suuroja T, Hussar U, Haviko T. Transport proteins in rats' renal corpuscle and tubules. Medicina (Kaunas). 2004;40(7):650-656.

7. Howard G, O'Leary DH, Zaccaro D, et al. Insulin sensitivity and atherosclerosis. The Insulin Resistance Atherosclerosis Study (IRAS) Investigators. Circulation. 1996;93(10):1809-1817.

8. Henriksen EJ. Improvement of insulin sensitivity by antagonism of the renin-angiotensin system. Am J Physiol Regul Integr Comp Physiol. 2007;293(3):R974-R980.

9. Folli F, Kahn CR, Hansen H, Bouchie JL, Feener EP. Angiotensin II inhibits insulin signaling in aortic smooth muscle cells at multiple levels. A potential role for serine phosphorylation in insulin/angiotensin II crosstalk. J Clin Invest. 1997;100(9):2158-2169.

10. Yusuf S, Sleight P, Pogue J, Bosch J, Davies R, Dagenais G. Effects of an angiotensin-converting-enzyme inhibitor, ramipril, on cardiovascular events in high-risk patients. N Engl J Med. 2000;342(3):145-153.

11. Fogari R, Zoppi A, Lazzari P, et al. ACE inhibition but not angiotensin II antagonism reduces plasma fibrinogen and insulin resistance in overweight hypertensive patients. $J$ Cardiovasc Pharmacol. 1998;32(4):616-620.

12. Andreozzi F, Laratta E, Sciacqua A, Perticone F, Sesti G. Angiotensin II impairs the insulin signaling pathway promoting production of nitric oxide by inducing phosphorylation of insulin receptor substrate- 1 on Ser312 and Ser616 in human umbilical vein endothelial cells. Circ Res. 2004;94(9):1211-1218.

13. Atkins KB, Johns D, Watts S, Clinton Webb C, Brosius FC 3rd. Decreased vascular glucose transporter expression and glucose uptake in DOCA-salt hypertension J Hypertens. 2001;19(9):1581-1587.

14. Park JL, Loberg RD, Duquaine D, et al. GLUT4 facilitative glucose transporter specifically and differentially contributes to agonist-induced vascular reactivity in mouse aorta. Arterioscler Thromb Vasc Biol. 2005;25(8):1596-1602.

15. Atkins KB, Prezkop A, Park JL, et al. Preserved expression of GLUT4 prevents enhanced agonist-induced vascular reactivity and MYPT1 phosphorylation in hypertensive mouse aorta. Am J Physiol Heart Circ Physiol. 2007;293(1):H402-H408.

16. de Araujo M, Seguro AC. Vasodilator agents protect against indinavir nephrotoxicity. Antivir Ther. 2003;8(4):295-299.

17. Davidson WD, Sackner MA. Simplification of the anthrone method for the determination of inulin in clearance studies. J Lab Clin Med. 1963;62:351-356.
18. Shiuchi T, Iwai M, Li HS, et al. Angiotensin II type-1 receptor blocker valsartan enhances insulin sensitivity in skeletal muscles of diabetic mice. Hypertension. 2004;43(5):1003-1010.

19. Sloniger JA, Saengsirisuwan V, Diehl CJ, Kim JS, Henriksen EJ. Selective angiotensin II receptor antagonism enhances whole-body insulin sensitivity and muscle glucose transport in hypertensive TG(mREN2)27 rats. Metabolism. 2005;54(12):1659-1668.

20. Ikenaga H, Bast JP, Fallet RW, Carmines PK. Exaggerated impact of ATP-sensitive $\mathrm{K}(+)$ channels on afferent arteriolar diameter in diabetes mellitus. J Am Soc Nephrol. 2000;11(7):1199-1207.

21. Folli F, Saad MJ, Velloso L, et al. Crosstalk between insulin and angiotensin II signalling systems. Exp Clin Endocrinol Diabetes. 1999; 107(2):133-139.

22. Widdop RE, Jones ES, Hannan RE, Gaspari TA. Angiotensin AT2 receptors: cardiovascular hope or hype? Br J Pharmacol. 2003;140(5):809-824.

23. Carey RM. Cardiovascular and renal regulation by the angiotensin type 2 receptor: the AT2 receptor comes of age. Hypertension. 2005; 45(5):840-844.

24. Zeng G, Nystrom FH, Ravichandran LV, et al. Roles for insulin receptor, PI3-kinase, and Akt in insulin-signaling pathways related to production of nitric oxide in human vascular endothelial cells. Circulation. 2000; 101(13):1539-1545.

25. Harrison-Bernard LM. The renal renin-angiotensin system. Adv Physiol Educ. 2009;33(4):270-274.

26. Beutler KT, Masilamani S, Turban S, et al. Long-term regulation of $\mathrm{ENaC}$ expression in kidney by angiotensin II. Hypertension. 2003; 41(5):1143-1150.

27. Hall JE, Coleman TG, Guyton AC, Kastner PR, Granger JP. Control of glomerular filtration rate by circulating angiotensin II. Am J Physiol. 1981;241(3):R190-R197.

28. Zhao D, Seth DM, Navar LG. Enhanced distal nephron sodium reabsorption in chronic angiotensin II-infused mice. Hypertension. 2009;54(1):120-126.

29. Wang CT, Chin SY, Navar LG. Impairment of pressure-natriuresis and renal autoregulation in ANG II-infused hypertensive rats. Am J Physiol Renal Physiol. 2009;279(2):F319-F325.

30. Hayabuchi Y, Davies NW, Standen NB. Angiotensin II inhibits rat arterial KATP channels by inhibiting steady-state protein kinase A activity and activating protein kinase Ce. J Physiol. 2001;530(Pt 2):193-205.

31. Sampson LJ, Hayabuchi Y, Standen NB, Dart C. Localize protein kinase A signaling to arterial ATP-sensitive potassium channels. Circ Res. 2004;95(10):1012-1018.

32. Vera T, Granger JP, Stec DE. Inhibition of bilirubin metabolism induces moderate hyperbilirubinemia and attenuates ANG II-dependent hypertension in mice. Am J Physiol Regul Integr Comp Physiol. 2009; 297(3):R738-R743.

33. Vera T, Stec DE. Moderate hyperbilirubinemia improves renal hemodynamics in ANG II-dependent hypertension. Am J Physiol Regul Integr Comp Physiol. 2010;299(4):R1044-R1049.

34. Hall JE. Hyperinsulinemia: a link between obesity and hypertension? Kidney Int. 1993;43(6):1402-1417.

35. Anderson EA, Mark AL. The vasodilator action of insulin. Implications for the insulin hypothesis of hypertension. Hypertension. 1993; 21(2):136-141.

36. Kirchner KA. Insulin increases loop segment chloride reabsorption in the euglycemic rat. Am J Physiol. 1998;255(6 Pt 2):F1206-F1213.

37. Eitle E, Hiranyachattada S, Wang H, Harris PJ. Inhibition of proximal tubular fluid absorption by nitric oxide and atrial natriuretic peptide in rat kidney. Am J Physiol. 1998;274(4 Pt 1):C1075-C1080.

38. García NH, Pomposiello SI, Garvin JL. Nitric oxide inhibits ADHstimulated osmotic water permeability in cortical collecting ducts. $\mathrm{Am}$ J Physiol. 1996;270(1 Pt 2):F206-F210.

39. Ortíz MC, Fortepiani LA, Ruiz-Marcos FM, Atucha NM, García-Estañ J. Role of AT1 receptors in the renal papillary effects of acute and chronic nitric oxide inhibition. Am J Physiol. 1998;274(3 Pt 2):R760-R766. 
Journal of Experimental Pharmacology

Dovepress

\section{Publish your work in this journal}

The Journal of Experimental Pharmacology is an international, peerreviewed, open access journal publishing original research, reports, reviews and commentaries on all areas of laboratory and experimental pharmacology. The manuscript management system is completely online and includes a very quick and fair peer-review system.

Submit your manuscript here: http://www.dovepress.com/journal-of-experimental-pharmacology-journal
Visit http://www.dovepress.com/testimonials.php to read real quotes from published authors. 